\title{
ANDREA SCHELLINO, La pensée de la décadence de Baudelaire à Nietszche
}

\section{Mariolina Bertini}

\section{(2) OpenEdition \\ 1 Journals}

\section{Edizione digitale}

URL: https://journals.openedition.org/studifrancesi/47464

DOI: $10.4000 /$ studifrancesi. 47464

ISSN: 2421-5856

\section{Editore}

Rosenberg \& Sellier

\section{Edizione cartacea}

Data di pubblicazione: 1 décembre 2021

Paginazione: 633-634

ISSN: 0039-2944

\section{Notizia bibliografica digitale}

Mariolina Bertini, «ANDREA ScheluIno, La pensée de la décadence de Baudelaire à Nietszche», Studi Francesi [Online], 195 (LXV | III) | 2021, online dal 01 décembre 2021, consultato il 07 décembre 2022. URL: http://journals.openedition.org/studifrancesi/47464; DOI: https://doi.org/10.4000/studifrancesi. 47464

Questo documento è stato generato automaticamente il 7 décembre 2022.

\section{(c)}

Creative Commons - Attribuzione - Non commerciale - Non opere derivate 4.0 Internazionale - CC BYNC-ND 4.0

https://creativecommons.org/licenses/by-nc-nd/4.0/ 


\title{
ANDREA SCHELLINO, La pensée de la décadence de Baudelaire à Nietszche
}

\author{
Mariolina Bertini
}

\section{NOTIZIA}

ANDREA SCHELLINO, La pensée de la décadence de Baudelaire à Nietszche, Paris, Classiques

Garnier, 2020, 655 pp.

1 Centrale per Baudelaire come per Nietzsche, l'idea di décadence presenta, nel pensiero di entrambi, un carattere fortemente ambivalente. In Baudelaire è associata infatti al trionfo del progresso materiale che determina il declino dell'arte e atrofizza spiritualmente l'umanità; ma è anche sinonimo di modernità, di quella modernità da cui il poeta dello Spleen de Paris è affascinato e ispirato al più alto grado. Per Nietzsche, la décadence, sviluppo estremo del romanticismo, è l'età dell'estetica wagneriana, di un erotismo mistico morbido e funereo, della confusione tra le arti, del prevalere degli effetti teatrali sulla sobrietà del Grande Stile. Tutti fenomeni negativi agli occhi del creatore di Zarathustra; che tuttavia preludono all'avvento di un salutare nihilismo della forza che spazzerà via $i$ valori superati del passato aprendo nuove strade all'umanità rigenerata.

2 Ma Baudelaire e Nietzsche non sono certamente i soli nel loro tempo a fare i conti con questo termine polivalente, dalle innumerevoli sfaccettature. Dall'estetica alla psicologia, dalla storia politica a quella letteraria, l'idea di décadence è onnipresente nella cultura europea a partire dalla metà del xix secolo e questo ricco e documentatissimo studio di Andrea Schellino ne esplora la fortuna ben al di là dei due autori presenti nel suo titolo.

La prima delle due parti in cui si divide questo volume è dedicata all'autore delle «Fleurs du mal: Baudelaire, poète et penseur de la décadence». Già i primi e più influenti esegeti di Baudelaire ricorrono alla nozione di décadence per definirlo: per Barbey d'Aurevilly il suo talento "est lui-même une fleur du mal venue dans les serres chaudes de la 
décadence»; Sainte-Beuve conia per lui la formula ingegnosa di «Aloïsius Bertrand de la décadence»; agli occhi di Paul Bourget, è "un homme de décadence» che si è trasformato in «théoricien de la décadence». Ma il termine décadence utilizzato da Barbey, Sainte-Beuve e Bourget ha già dietro di sé una lunga storia. Andrea Schellino molto opportunamente la ripercorre, risalendo indietro nel tempo: attraverso il lessico di Voltaire, di Montesquieu, di Chateaubriand, e poi nella critica di Nisard e di Villemain, la parola décadence si carica di impliciti riferimenti storici e di sfumature di cui bisogna tener conto per studiarne l'applicazione all'opera di Baudelaire da parte dei suoi critici e l'uso da parte del poeta stesso. Sfondo storico e contesto culturale, esplorati capillarmente, contribuiscono all'analisi dettagliata che Schellino ci offre poi della visione baudelairiana della décadence, dedicando una particolare attenzione al rapporto del poeta con Sainte-Beuve. È un rapporto che nasce e si consolida nella consapevolezza condivisa di vivere, tra nostalgia e smarrimento, il declino irreversibile del movimento romantico; declino che è a sua volta una décadence, dalle innumerevoli nuances estetiche e morali. Alla condizione di Baudelaire, "figlio spirituale" di SainteBeuve spasmodicamente attento agli ambigui giudizi sulla sua poesia di quel padre ideale, Schellino dedica un capitolo approfondito, che è quasi un'autonoma monografia su un nodo problematico di estremo interesse.

4 La seconda parte del volume, «Nietzsche penseur de la décadence», ricostruisce le tappe successive attraverso le quali evolve il rapporto di Nietzsche con la cultura francese, soprattutto (anche se non esclusivamente) con quella contemporanea. A partire dal 1883-84, il filosofo si dedica alla lettura di Baudelaire, dei Goncourt, di Flaubert, Gautier, Hugo e altri autori francesi, senza trascurare critici e storici come Taine, Renan, Brunetière e il severo fustigatore della décadence Scherer. È insieme attratto ma anche irritato dal pessimismo, dal cinismo esasperato, dal nihilismo della cerchia dei Goncourt e di Flaubert; l'analisi che Bourget ne offre nei suoi Essais de psychologie contemporaine è secondo lui convincente, ma l'analista stesso gli sembra contaminato dalla malattia spirituale che tanto sottilmente descrive. Proprio nelle pagine di Bourget, Nietzsche incontra un'immagine di Baudelaire destinata a segnarlo durevolmente. Per Bourget, Baudelaire è colui che incarna più lucidamente e consapevolmente il pessimismo e la décadence. Nietzsche è come folgorato dalla constatazione delle affinità del poeta francese con Wagner. Quando, nel 1888, leggendo le CEuvres posthumes di Baudelaire, scopre il wagnerismo dell'autore delle Fleurs du mal, ha la conferma di una sua antica intuizione: Baudelaire è "una sorta di Wagner senza musica". Nella costellazione Wagner-Baudelaire Nietzsche riconosce così un'estetica che è l'esito estremo del romanticismo: un pericoloso concentrato di misticismo, erotismo, pessimismo e pulsione di morte, che rischia di contrastare la resurrezione di quegli istinti vitali dai quali dipende la rinascita dell'umanità. Impossibile in questa sede riassumere la puntualissima, esauriente ricostruzione che il volume di Andrea Schellino offre di tutte le tracce della lettura di Baudelaire nell'opera di Nietzsche, e di tutte le opere critiche o saggistiche che hanno svolto un ruolo di mediazione nel rapporto di Nietzsche con la cultura francese. Ci limiteremo a notare che questo lavoro di assidua perlustrazione dei testi e delle letture del filosofo (come dei testi e delle letture di Baudelaire nella prima parte) è costantemente integrato da un serrato dialogo con la critica di oggi, dialogo testimoniato anche da una bibliografia accuratissima di un centinaio di pagine. Grazie alla ricchezza dei riferimenti, all'ampiezza dell'orizzonte di ricerca e al rispetto della complessità dei problemi trattati, credo si possa affermare che La pensée de la décadence de Baudelaire à Nietzsche 
segna una data importante negli studi su entrambi gli autori ed è destinato ad affermarsi come un prezioso punto di riferimento per tutti gli studiosi della décadence. 